\title{
Anxiety and depression amongst patients enrolled in a public sector antiretroviral treatment programme in South Africa: a cross- sectional study
}

Michele Pappin ${ }^{1 *}+$ Edwin Wouters ${ }^{2+}$ and Frederik LR Booysen ${ }^{3+}$

\begin{abstract}
Background: HIV/AIDS and depression are projected to be the two leading causes of disability by 2030. HIV/AIDS and anxiety/depression are interlinked. People suffering from depression may be more likely to engage in risky sexual behaviour, and therefore at greater risk of contracting HIV. An HIV + diagnosis may trigger symptoms of anxiety and depression, which may in turn result in risky sexual behaviour and the spread of HIV. This study explores correlates of anxiety and depression in patients enrolled in a public sector ART programme in South Africa.

Methods: Interviews were conducted with 716 patients initiating ART at twelve public health care facilities in the Free State. Symptoms of anxiety and depression were measured using the Hospital Anxiety and Depression Scale (HADS). An 8+ cut-off was used to identify possible cases of anxiety and depression. Multivariate logistic regression analysis, using STATA Version 11, was performed to identify correlates of anxiety and depression.

Results: The prevalence of symptoms of respectively anxiety and depression amongst this study population in the Free State was 30.6\% and 25.4\%. The multivariate logistic regression analyses identified five correlates of symptoms of anxiety and depression. Disruptive side effects $(\mathrm{OR}=3.62, \mathrm{Cl} 1.95-6.74)$ and avoidant coping $(\mathrm{OR}=1.42, \mathrm{Cl} 1.22-$ 1.65) were associated with a greater number of symptoms of anxiety. Stigma was associated with an increase in symptoms of anxiety $(\mathrm{OR}=1.14, \mathrm{Cl} 1.07-1.21)$ and of depression $(\mathrm{OR}=1.13, \mathrm{Cl} 1.06-1.20)$, while being a widow (OR $=0.30, \mathrm{Cl} 0.13-0.69)$ and participating in a support group $(\mathrm{OR}=0.21, \mathrm{Cl} 0.05-0.99)$ were associated with decreased symptoms of depression.

Conclusions: The findings from the study provide valuable insights into the psychosocial aspects of the Free State public-sector ART programme. Combined with the literature on the intricate link between mental health problems and treatment outcomes our results emphasise firstly, the necessity that resources be allocated for both screening and treating mental health problems and, secondly, the need for interventions that will encourage support-group participation, address ART side effects, reduce maladaptive coping styles, and minimise the stigma associated with symptoms of anxiety and/or depression.
\end{abstract}

\section{Background}

HIV/AIDS and depression are projected to be the world's two leading causes of disability by 2030 [1]. Worldwide, 33 million people are currently living with HIV. In 2009, there were an estimated 2.6 million new

\footnotetext{
* Correspondence: pappinm@gmail.com

+ Contributed equally

${ }^{1}$ Centre for Development Support, University of the Free State, Bloemfontein, South Africa

Full list of author information is available at the end of the article
}

HIV infections and 1.8 million deaths due to AIDS [2]. Depression, on the other hand, affects 121 million people globally [3].

Importantly, HIV/AIDS and anxiety/depression are interlinked. People suffering from depression may be more likely to engage in risky sexual behaviour, and they are therefore at greater risk of contracting HIV [4-6]. Conversely, an HIV + diagnosis may trigger symptoms of anxiety and depression $[7,8]$, which could once

\section{Biomed Central}


again lead to risky sexual behaviour and the spreading of the virus. In addition, studies have shown that people suffering from depression are less likely to adhere to treatment - treatment for both mental illness and for antiretroviral treatment (ART) [9]. Depression may therefore lead to non-adherence to ART and result in poorer health. Unfortunately, more than half of the HIV + population that suffer from depression have not received an official diagnosis of their depression [10].

Recent studies on the prevalence of anxiety and depression in HIV/AIDS patients who are on ART in resource-limited settings confirm this link. Symptoms of anxiety and depression among 386 people initiating ART in Brazil were measured using the Hospital, Anxiety and Depression Scale (HADS) $(\leq 10)$. The prevalence of anxiety and depression, respectively, was $35.8 \%$ and $21.8 \%$ [11]. A study in Uganda assessed the prevalence of symptoms of depression in 1017 patients eligible for ART using the Centre for Epidemiologic Studies Depression Scale $(\geq 23)$. The prevalence of depression was $47 \%$ [12].

A study in Cape Town, South Africa, assessed the prevalence of psychiatric disorders using the Mini International Neuropsychiatric Interview among 149 recently diagnosed HIV/AIDS patients. The prevalence of anxiety was $6.7 \%$ and that of depression was $34.9 \%$ [13,14], which highlights the extent of anxiety and/or depression in $\mathrm{HIV}+$ populations. Prevalence rates must however be interpreted with caution as location of study, study population and different types of measures make it impossible to arrive at a single prevalence rate for anxiety or depression. In addition, self-reported measures and psychiatric screening tools- such as HADS- report higher rates of depression than do diagnostic evaluations [15].

Researchers have identified a broad spectrum of protective and risk factors associated with anxiety and depression in HIV + populations. Apart from sociodemographic characteristics, such as age and gender, correlates include socio-economic (education, income, poverty), behavioural (alcohol use, sexual activity), psychosocial (disclosure, family support, prior depression, family history of depression, positive coping, stigma, and social support) and health-related factors (pain, health status, time on treatment) [11,13,16-28].

The complex interrelationship between these protective and risk factors correlated with mental health, the occurrence of anxiety and depression, and the health outcomes of ART recipients all render this issue an urgent research priority. However, previous research does not - in one and the same study - simultaneously incorporate all correlates of anxiety and depression in people receiving ART, despite the fact that such a comprehensive framework and knowledge is vital with a view to developing appropriate interventions. This study fills this particular research gap by simultaneously assessing the impact of demographic, socio-economic, behavioural, psychosocial, and health variables on symptoms of anxiety and depression in a population of public sector ART patients in the Free State Province of South Africa.

\section{Methods}

Data

This study is part of a cohort study entitled "Effective Aids Treatment and Support in the Free State (FEATS)" that was conducted by the Centre for Health Systems Research and Development (CHSR\&D) of the University of the Free State (UFS). The study was approved by the Ethics Committee of the Faculty of Health Sciences of the UFS [ETOVS 145/07, DOH-27-0907-2025]. Study participants were recruited in 2007/08 from twelve public ART clinics in five districts in the Free State. Inclusion criteria were being eighteen years or older, having commenced ART in the five weeks prior to recruitment, and, residing in the town or village where the particular health facility was located. Data were collected by trained enumerators using structured face-to-face interviews once written informed consent had been obtained from study participants. The target sample size was 648 study participants and households. Because not all households consented to participate in the study, additional patients were recruited, this resulting in a total of 716 study participants.

\section{Measures}

As specified in detail in the Appendix below, data on demographic, socio-economic, behavioural, psychosocial and health variables were collected. Socio-economic variables included: 'education level', 'dwelling type ', financial statuses, and 'food supplements'. Behavioural variables comprised: 'use of alcohol', 'use of tobacco', 'use of dagga', and 'engagement in sexual activity'. Psychosocial factors included: 'stigma', 'coping', and 'psychosocial support'. Psychosocial support included the variables 'treatment buddy', 'community worker', 'support group' and 'disclosure' [29,30]. Health-related variables included 'health-related quality of life' (EQ-VAS) $[31,32]$, 'time since first HIV + test', and 'ART side effects'.

In this study, anxiety and depression referred to selfreported symptoms of anxiety and depression and not Axis I anxiety and depressive clinical disorders. Symptoms of anxiety and depression were measured using HADS, which was originally developed as a self-administered tool to assess anxiety and depression in medically ill patients [33]. The scale contains four response options and comprises two subscales of seven questions 
each. The subscales measure anxiety and depression respectively and range from $0-21$, with a higher score denoting a greater number of symptoms of either anxiety or depression. Previous psychometric investigations have shown that HADS achieves both good internal consistency and test-retest reliabilities, is sensitive to change, and provides valid assessments in HIV-positive populations $[34,35]$ in resource-limited settings [36,37]. For the purposes of this study, the instrument was translated into SeSotho. The Cronbach's alphas for the subscales were 0.66 for anxiety and 0.61 for depression [38]. In this study, HADS scores were converted into a binary categorical variable, with an $8+$ score being used to identify possible cases of clinical anxiety and depression [33,34]. A study in Brazil of HIV + women also used a score of greater than 7 to identify symptoms of anxiety or depression [36,37]. A review of the psychometric properties of HADS moreover found that "[O] ptimal balance between sensitivity and specificity for HADS as a screening instrument was achieved most frequently at a cut-off score of $8+$ for both HADS-A[nxiety] and HADS-D[epression]" [39].

\section{Data analysis}

STATA Version 11 was used to perform the statistical data analysis. Firstly, descriptive statistics of the anxiety and depression measures were generated with the aim of assessing the prevalence of anxiety and depression in the study population. Secondly, descriptive statistics of sociodemographic and ART characteristics of study participants were compiled. Finally, two sets of multivariate logistic regression analyses were run, using anxiety and depression as separate dependent variables to investigate correlates of anxiety and depressive symptoms independently. A literature review on HIV/AIDS, antiretroviral treatment, and anxiety and depression informed the specification of the multivariate logistic regression models $[11,25,26,40,41]$. The independent variables in the multivariate regression models were: residential district, gender, age, marital status, education level, dwelling type, treatment buddy, community worker, support group, positive coping, avoidant coping, seeking-social-support coping, stigma, disclosure, use of alcohol, use of tobacco, use of dagga, sexual activity, financial status, food supplements, time since first HIV test, ART side effects and health-related quality of life (EQ-VAS).

\section{Results}

The majority of the study participants were black (98.4\%) and female (75.7\%). The mean age of the study participants was 37 years, and the median age was 36 years [IQR: $30.79-42.79]$. Participants were mostly single (41.5\%), while $23.7 \%$ were living with a spouse or partner, $14.6 \%$ were widowed and $10.6 \%$ were separated or divorced. The majority of the study participants lived in formal dwellings (66.6\%) and 19.5\% lived in informal dwellings. Most study participants had some education, mainly some secondary $(45.8 \%)$ or primary education $(31.0 \%)$. All the study participants had commenced ART, and the mean treatment duration was 37.7 days, with a median of 30 days [IQR: 18.0-46.5]. The prevalence of symptoms of anxiety was $30.6 \%$ and that for depression was $25.4 \%$.

\section{Correlates of anxiety}

The multivariate logistic regression analysis identified the following variables as correlates of symptoms of anxiety in people receiving ART (Table 1). HIV + patients who experienced very disruptive side effects from ART reported more of the symptoms of anxiety than did patients who had not reported side effects $(\mathrm{OR}=3.62$, CI 1.95-6.74). An avoidant coping style ( $\mathrm{OR}=1.42$, CI 1.22$1.65)$ and stigma (OR $=1.14$, CI 1.07-1.21) were also positively correlated with symptoms of anxiety. Finally, the longer study participants had known their HIV status, the more symptoms of anxiety they were likely to have experienced $(\mathrm{OR}=1.01, \mathrm{CI} 1.00-1.02)$.

\section{Correlates of depression}

The multivariate logistic regression analysis identified the following variables as correlates of depressive symptoms in people receiving ART (Table 2). Stigma was positively correlated with symptoms of depression (OR $=1.13$, CI 1.06-1.20). The longer participants had known their HIV + status, the more symptoms of depression they were likely to have been experiencing $(\mathrm{OR}=1.02$, CI 1.01-1.03). Respondents who participated in a support group were less likely to have been depressed than those who had not belonged to a support group ( $\mathrm{OR}=0.21$, CI 0.05-0.99). Finally, widowed study participants experienced fewer symptoms of depression than those who were single $(\mathrm{OR}=0.30, \mathrm{CI}$ 0.13-0.69).

\section{Discussion}

This study represents one of a few studies that systematically and simultaneously investigated correlates of symptoms of anxiety and depression in patients enrolled in a public sector ART programme in a resource-limited setting. Two risk factors, namely severe side effects and avoidant coping, were correlated with increased symptoms of anxiety, while a protective factor-participating in a support group- was associated with a decrease in symptoms of depression. Another risk factor, namely stigma, was associated with an increase in symptoms of both anxiety and depression.

Very disruptive ART side effects were correlated with more of the symptoms of anxiety amongst our study 
Table 1 Multivariate logistic regression analysis of factors correlated with symptoms of anxiety in HIV + respondents on ARV treatment

\begin{tabular}{|c|c|c|c|}
\hline & Odds Ratio & P-value & $95 \%$ conf. Interval \\
\hline \multicolumn{4}{|c|}{ District (comparison group = Lejweleputswa) } \\
\hline Motheo & 1.29 & & $0.59-2.80$ \\
\hline Fezile Dabi & 1.06 & & $0.51-2.20$ \\
\hline Thabo Mofutsanyane & 0.89 & & $0.47-1.71$ \\
\hline Xhariep & 3.98 & & $0.83-19.16$ \\
\hline Female & 0.70 & & $0.38-1.28$ \\
\hline \multicolumn{4}{|c|}{ Age (comparison group = under 30) } \\
\hline 30-34 years & 0.79 & & $0.35-1.80$ \\
\hline 35-39 years & 0.52 & & $0.23-1.16$ \\
\hline 40-44 years & 1.13 & & $0.50-2.54$ \\
\hline $45+$ years & 0.72 & & $0.30-1.72$ \\
\hline \multicolumn{4}{|c|}{ Marital status (comparison group = single) } \\
\hline Cohabiting & 0.55 & & $0.27-1.11$ \\
\hline Not cohabiting & 0.72 & & $0.34-1.56$ \\
\hline Widowed & 0.65 & & $0.30-1.41$ \\
\hline Separated or divorced & 0.76 & & $0.31-1.85$ \\
\hline \multicolumn{4}{|c|}{ Education (comparison group = none) } \\
\hline Primary & 0.65 & & $0.20-2.15$ \\
\hline Some secondary & 0.38 & & $0.11-1.27$ \\
\hline Matric and post-matric & 0.49 & & $0.14-1.78$ \\
\hline \multicolumn{4}{|c|}{ Dwelling (comparison group = formal dwelling) } \\
\hline Informal & 0.92 & & $0.48-1.74$ \\
\hline Traditional & 0.69 & & $0.27-1.72$ \\
\hline Other & 0.41 & & $0.17-1.00$ \\
\hline Treatment buddy (yes/no) & 0.91 & & $0.67-1.25$ \\
\hline Community worker (yes/no) & 0.79 & & $0.29-2.19$ \\
\hline Support group (yes/no) & 0.79 & & $0.20-3.18$ \\
\hline Positive coping & 0.88 & & $0.55-1.41$ \\
\hline Avoidant coping & 1.42 & ** & $1.22-1.65$ \\
\hline Seeking social-support coping & 0.73 & & $0.54-1.00$ \\
\hline Stigma scale & 1.14 & ** & $1.07-1.21$ \\
\hline \multicolumn{4}{|c|}{ Disclosure (comparison group = none) } \\
\hline Disclosed to some & 2.97 & & $0.56-15.83$ \\
\hline Disclosed to all & 4.33 & & $0.92-20.37$ \\
\hline Drink alcohol (yes/no) & 0.69 & & $0.30-1.55$ \\
\hline Smoke tobacco (yes/no) & 1.05 & & $0.42-2.63$ \\
\hline Smoke dagga (yes/no) & 0.43 & & $0.10-1.94$ \\
\hline \multicolumn{4}{|c|}{ Sexual activity (comparison group = no sex) } \\
\hline Always use a condom & 1.52 & & $0.91-2.54$ \\
\hline Inconsistent condom use & 1.51 & & $0.58-3.93$ \\
\hline Never use a condom & 0.99 & & $0.18-5.36$ \\
\hline \multicolumn{4}{|c|}{ Financial status (comparison group = disability grant) } \\
\hline Old-age pension & 1.63 & & $0.48-5.53$ \\
\hline Child grant & 2.12 & & $0.45-9.92$ \\
\hline Employed & 0.75 & & $0.37-1.52$ \\
\hline Support within the household & 0.64 & & $0.32-1.27$ \\
\hline
\end{tabular}


Table 1 Multivariate logistic regression analysis of factors correlated with symptoms of anxiety in HIV + respondents on ARV treatment (Continued)

\begin{tabular}{|c|c|c|c|}
\hline Support outside the household & 0.74 & & $0.30-1.83$ \\
\hline Other & 1.30 & & $0.57-2.95$ \\
\hline \multicolumn{4}{|c|}{ Food supplements (comparison group = never) } \\
\hline Previously & 0.41 & & $0.15-1.17$ \\
\hline Currently & 0.36 & & $0.12-1.06$ \\
\hline Time since first HIV + test & 1.01 & * & $1.00-1.02$ \\
\hline \multicolumn{4}{|c|}{ Side effects (comparison group = no side effects) } \\
\hline Somewhat disruptive side effects & 1.76 & & $0.94-3.31$ \\
\hline Very disruptive side effects & 3.62 & ** & $1.95-6.74$ \\
\hline Health-related quality of life (EQ-VAS) & 0.99 & & $0.98-1.01$ \\
\hline Sample size & & & 499 \\
\hline Wald-statistic & & & 106.8 \\
\hline P-value & & & $<0.001$ \\
\hline R 2 & & & 0.22 \\
\hline$\%$ successfully predicted & & & 78.56 \\
\hline
\end{tabular}

participants. Similarly, another study on ART in the Free State found that adverse side effects of treatment negatively affected the emotional well-being of the patients. The authors thus recommended that health care workers be vigilant regarding possible adverse side effects of treatment [42].

Our study did not find an association between coping strategies and depression [13,25,26,43]. However, unlike previous research, this study did investigate the association between coping strategies and anxiety. In this study, avoidant coping was correlated with a greater number of the symptoms of anxiety. It has been suggested that coping strategies of patients should be identified, and that patients using maladaptive strategies should receive therapeutic counseling [25].

Participating in a support group was associated with fewer symptoms of depression. This finding is in agreement with a study conducted in Thailand where low levels of social support were associated with increased levels of depression [19]. Social support is a protective coping mechanism that may assist HIV + people in solving problems and in expressing emotions, thereby reducing psychological distress [44-46].

In this study, perceived stigma was associated with symptoms both of anxiety and depression. This outcome confirms the findings from the literature that stigma is an important risk factor associated with depression $[17,18,21,41]$. The finding that stigma is associated with anxiety adds new evidence to the literature on the debilitating role that stigma may play in the lives of people receiving ART.
Whereas it is well established that widows and widowers face a greater risk of depression, especially in the immediate aftermath of bereavement [47], this study found widowhood to offer protection against symptoms of depression, which may be attributed to access to both material support and especially psychosocial support within their extended family and kinship networks [48-50].

The study has the following limitations; firstly, study participants were drawn only from those HIV + individuals who had gained access to the public sector antiretroviral treatment programme and had successfully completed drug-readiness training. Patients suffering from anxiety and depression may be less likely to seek care, complete drug readiness, and initiate treatment. They are thus under-represented in this study. Secondly, because the empirical analysis was based on selfreported information, the measures may not be completely accurate. Particularly problematic variables include self-reported side effects and sexual behaviour. Thirdly, this was a cross-sectional study, so that all the data were measured at the same time. Consequently, causality between symptoms of anxiety and depression and their correlates could not be firmly established. Fourthly, although according to some authors "the HADS appears to represent the best currently available self-report to reliably and validly assess anxiety and depression in HIV infected patients" [34], it has not yet been validated among HIV + patients initiating ART in South Africa. In the fifth instance, the Cronbach's alpha for the two subscales is below the threshold of 0.70 . The scale may 
Table 2 Multivariate logistic regression analysis of factors correlated with symptoms of depression in HIV + respondents on ARV treatment

\begin{tabular}{|c|c|c|c|}
\hline & Odds Ratio & P-value & $95 \%$ conf. Interval \\
\hline \multicolumn{4}{|c|}{ District (comparison group = Lejweleputswa) } \\
\hline Motheo & 0.91 & & $0.42-1.98$ \\
\hline Fezile Dabi & 0.84 & & $0.37-1.89$ \\
\hline Thabo Mofutsanyane & 1.08 & & $0.54-2.14$ \\
\hline Xhariep & 0.41 & & $0.04-3.90$ \\
\hline Female & 0.93 & & $0.50-1.72$ \\
\hline \multicolumn{4}{|c|}{ Age (comparison group = under 30) } \\
\hline 30-34 years & 1.21 & & $0.54-2.70$ \\
\hline 35-39 years & 1.72 & & $0.76-3.87$ \\
\hline 40-44 years & 1.68 & & $0.73-3.89$ \\
\hline $45+$ years & 2.30 & & $0.93-5.67$ \\
\hline \multicolumn{4}{|c|}{ Marital status (comparison group = single) } \\
\hline Cohabiting & 0.75 & & $0.38-1.48$ \\
\hline Not cohabiting & 0.64 & & $0.26-1.59$ \\
\hline Widowed & 0.30 & * & $0.13-0.69$ \\
\hline Separated or divorced & 0.89 & & $0.40-1.99$ \\
\hline \multicolumn{4}{|c|}{ Education (comparison group = none) } \\
\hline Primary & 1.87 & & $0.44-7.99$ \\
\hline Some secondary & 1.24 & & $0.29-5.34$ \\
\hline Matric and post-matric & 1.11 & & $0.23-5.30$ \\
\hline \multicolumn{4}{|c|}{ Dwelling (comparison group = formal dwelling) } \\
\hline Informal & 0.82 & & $0.39-1.74$ \\
\hline Traditional & 1.11 & & $0.48-2.55$ \\
\hline Other & 0.92 & & $0.39-2.15$ \\
\hline Treatment buddy (yes/no) & 1.20 & & $0.88-1.64$ \\
\hline Community worker (yes/no) & 0.91 & & $0.30-2.71$ \\
\hline Support group (yes/no) & 0.21 & * & $0.05-0.99$ \\
\hline Positive coping & 0.68 & & $0.44-1.06$ \\
\hline Avoidant coping & 1.01 & & $0.98-1.04$ \\
\hline Seeking social-support group & 1.05 & & $0.75-1.49$ \\
\hline Stigma scale & 1.13 & ** & $1.06-1.20$ \\
\hline \multicolumn{4}{|c|}{ Disclosure (comparison group = none) } \\
\hline Disclosed to some & 0.43 & & $0.09-2.08$ \\
\hline Disclosed to all & 1.18 & & $0.29-4.90$ \\
\hline Drink alcohol (yes/no) & 0.83 & & $0.38-1.79$ \\
\hline Smoke tobacco (yes/no) & 1.61 & & $0.66-3.93$ \\
\hline Smoke dagga (yes/no) & 0.39 & & $0.10-1.50$ \\
\hline \multicolumn{4}{|c|}{ Sexual activity (comparison group = no sex) } \\
\hline Always use a condom & 0.90 & & $0.53-1.51$ \\
\hline Inconsistent condom use & 1.12 & & $0.45-2.77$ \\
\hline Never use a condom & 0.93 & & $0.20-4.35$ \\
\hline \multicolumn{4}{|c|}{ Financial status (comparison group = disability grant) } \\
\hline Old-age pension & 0.64 & & $0.19-2.14$ \\
\hline Child grant & 1.47 & & $0.31-7.01$ \\
\hline Employed & 0.74 & & $0.37-1.49$ \\
\hline Support within the household & 0.73 & & $0.36-1.49$ \\
\hline
\end{tabular}


Table 2 Multivariate logistic regression analysis of factors correlated with symptoms of depression in HIV + respondents on ARV treatment (Continued)

\begin{tabular}{lll}
\hline Support outside the household & 1.11 & $0.44-2.78$ \\
\hline Other & 0.68 & $0.26-1.78$ \\
\hline Food supplements (comparison group = never) & & $0.18-1.76$ \\
\hline Previously & 0.56 & $0.10-1.00$ \\
\hline Currently & 0.32 & $1.01-1.03$ \\
\hline Time since first HIV + test & 1.02 & $0.54-2.05$ \\
\hline Side effects (comparison group = no side effects) & & $0.92-3.46$ \\
\hline Somewhat disruptive side effects & 1.05 & $0.97-1.00$ \\
\hline Very disruptive side effects & 1.79 & 499 \\
\hline Health-related quality of life (EQ-VAS) & 0.99 & 82.26 \\
\hline Sample size & & $<0.001$ \\
\hline Wald-statistic & & 0.17 \\
\hline P-value & & 78.96 \\
\hline R 2 & & \\
\hline$\%$ successfully predicted & & \\
\hline Note: *p-value $\leq 0.05$ & & \\
**p-value $\leq 0.01$ & & \\
\hline
\end{tabular}

thus not be all that reliable [38]. For the purposes of this study, the instrument was translated into SeSotho. Further research is consequently required so as to ensure the reliability and validity of the translated version. Finally, by using a low cut-off of $8+$ the study may be missing important correlates of mild (8-10), moderate (11-15) and particularly severe (16-21) symptoms of anxiety and depression [51]. The small number of severe cases observed in this study [anxiety $n=7$, depression $n$ $=4]$ precluded meaningful statistical analysis. In larger samples, multivariate multinomial logistic regression offers a method by which jointly to determine factors correlated with each of the four classes of symptoms of anxiety and depression.

\section{Conclusions}

This study sheds some light on the nature of symptoms of anxiety and depression in patients receiving ART in a resource-limited setting. The prevalence of symptoms of anxiety was $30.6 \%$ and that of depression was $25.4 \%$. Severe side effects of ART, avoidant coping strategies, participating in a support group and stigma are correlates of anxiety and/or depression.

This study has both theoretical and practical implications.

From a theoretical point of view, the impact of ART side effects, coping strategies, support groups and stigmatisation on the mental health of HIV/AIDS patients draws attention to the inter-linked nature of treatment aspects, social support and mental health in achieving durable ART success. However, further research is required so as fully to disentangle the complex interrelationships between these social, mental and physical aspects of public-sector ART in high HIV-prevalence resource-limited settings.

From the perspectives of practical policy and management, the study findings provide valuable insights into psychosocial aspects of the Free State public-sector ART programme. Combined with the literature on the intricate link between mental health problems and treatment outcomes our results emphasise firstly, the necessity that resources be allocated for screening and treating mental-health problems, and, secondly, that interventions are required that will encourage support-group participation, address ART side effects, reduce maladaptive coping styles and minimise stigma associated with symptoms of anxiety and/or depression.

\section{Appendix: Details of measures}

Data on demographic, socio-economic, behavioural, psychosocial and health variables were collected. Demographic variables included 'district of residence', 'gender', 'age' and 'marital status'. The variable marital status comprised 'single', 'cohabiting', 'not-cohabiting', 'widowed', and 'separated or divorced'. 'Single' refers to participants without any type of partner, 'cohabiting' refers to participants who lived with a partner irrespective of whether or not they were married, and 'not-cohabiting' refers to participants whose partners (married or not) lived elsewhere at the time of the interview.

Socio-economic variables included 'education level', 'dwelling type', 'financial status', and 'food supplements'. Education level comprised four categories: 'none', 'primary', 'some secondary', 'matric' (Grade 12) and 'post- 
matric'. Dwelling type comprised four categories: 'formal', 'informal', 'traditional', and, 'other'. Other included 'a flat or apartment in a block of flats', 'a dwelling in a backyard' and 'a hostel'. Financial status refers to how participants usually support themselves. The seven categories were: 'disability grant', 'old-age pension', 'childsupport grant', 'employed', 'support within the household', 'support outside the household', and,'other'. The variable food supplements referred to the respondents' having received food supplements as part of the government's ARV treatment programme. The categories were 'never', 'previously' or 'currently'.

Behavioural variables included 'use of alcohol', 'use of tobacco', 'use of dagga', and 'engagement in sexual activity'. 'Use of alcohol', 'use of tobacco', and 'use of dagga' were dichotomous variables, referring only to whether or not a person engaged in the activity rather than establishing the extent to which the person was doing so. Sexual activity referred to whether or not participants had had sexual intercourse in the six months prior to the study, and if so, whether they had used a condom. The four categories for this variable were: 'no sex', 'always used condom', 'inconsistent condom use' and 'never used a condom'.

Psychosocial factors included 'stigma', 'coping', and 'psychosocial support'. The stigma scale was generated from eight items in the questionnaire, asking respondents about the extent to which they agreed or disagreed with perceptions that they or others had regarding HIV and AIDS. The possible responses were: 'strongly disagree', 'disagree', 'agree' or 'strongly agree' [52]. The scale reported an alpha of 0.70 [31]. Three coping behaviours were measured: 'positive', 'avoidant' and 'seeking social support coping styles'. Respondents were asked to describe how they were currently (at the time of the study) dealing with living with HIV and AIDS by answering 'yes' or 'no' to sixteen statements. The statements were taken from a study conducted in the United States between 1988 and 1989. In that study, a factor analysis of the sixteen coping behaviours of 1031 people with AIDS revealed 'positive', 'avoidant' and 'seeking social support' to be three main coping mechanisms of people with AIDS [26]. Psychosocial support included four questions concerning 'a treatment buddy', 'community worker', 'support group' and 'disclosure', the first three of which were dichotomous variables. 'Treatment buddy' refers to whether the respondent at the time of the present study had a treatment buddy; 'community worker' denotes whether the participant at the time had a community worker visiting the participant at home; and 'support group' refers to whether the participant at the time of the study belonged to a support group. 'Disclosure' refers to the extent to which participants had disclosed to the three most important people in their lives, with response categories of 'none', 'some' and 'all'.

Health variables included 'health-related quality of life' (EQ-VAS), 'time since first HIV + test', and 'side effects'. 'EQ-VAS' is a visual analogue scale that measures a participant's health "today" and ranges from $0 \%$ (worst health) to $100 \%$ (best health). 'Time since first HIV + test' refers to the number of months the study participant had known their HIV + status. 'Side effects' refer to whether the participant experienced side effects from ART, and, if so, how disruptive these side effects were: 'no side effects', 'somewhat disruptive' or 'very disruptive'.

\section{Acknowledgements}

The study was funded by the Research Committee of the World Bank, The Bank Netherlands Program Partnership, the WB-DfiD 'Evaluation of the Community Response to HIV and AIDS', the Health Economics and Aids Research Division (HEARD) at the University of KwaZulu-Natal, the University of the Free State (UFS), and, the National Research Foundation (NRF) of South Africa. The findings, interpretations and conclusions in the article are those of the authors and do not reflect the views of the particular funding agencies.

\section{Author details}

'Centre for Development Support, University of the Free State, Bloemfontein, South Africa. ${ }^{2}$ Research Centre for Longitudinal and Life Course Studies (CELLO), University of Antwerp, Antwerp, Belgium. ${ }^{3}$ Department of Economics, University of the Free State, Bloemfontein, South Africa.

\section{Authors' contributions}

MP: Analysis of data, interpretation of results and original manuscript. EW: Revision of manuscript for important intellectual content. FLRB: Revision of manuscript for important intellectual content. All of the above authors read and approved the final manuscript.

\section{Competing interests}

The authors declare that they have no competing interests.

Received: 24 May 2011 Accepted: 27 March 2012

Published: 27 March 2012

\section{References}

1. Mathers $C D$, Loncar D: Projections of global mortality and burden of disease from 2002 to 2030. Plos Medicine 2006, 3(11):2011-2030.

2. UNAIDS: Global report: UNAIDS report on the global aids epidemic 2010. [http://www.unaids.org/documents/20101123_Globalreport_em.pdf].

3. World Health Organisation: Health topics: Depression.[http://www.who.int/ mentalhealth/management/depression/definition/]

4. Gupta R, Dandu M, Packel L, Rutherford G, Leiter K, Phaladze N, Korte FP, lacopino V, Weiser SD: Depression and HIV in Botswana: A populationbased study on gender-specific socio-economic and behavioral correlates. PloS One 2010, 5(12):e14252.

5. Smit J, Myer L, Middelkoop K, Seedat S, Wood R, Bekker LG, Stein DJ: Mental health and sexual risk behaviours in a South African township: A community-based cross-sectional study. Public Health 2006, 120(6):534-542.

6. Meade CS, Sikkema KJ: HIV risk behavior among adults with severe mental illness: A systematic review. Clin Psychol Rev 2005, 25(4):433-457.

7. Boarts JM, Buckley-Fischer BA, Armelie AP, Bogart LM, Delahanty DL: The impact of HIV diagnosis-related vs. non-diagnosis related trauma on PTSD, depression, medication adherence, and HIV disease markers. Journal of Evidence-Based Social Work 2009, 6(1):4-16.

8. Hand GA, Phillips KD, Dudgeon WD: Perceived stress in HIV-infected individuals: Physiological and psychological correlates. AIDS Care 2006, 18:1011-1017. 
9. Horberg MA, Silverberg MJ, Hurley LB, Towner WJ, Klein DB, BersoffMatcha S, Weinberg WG, Antoniskis D, Mogyoros M, Dodge WT, Dobrinich R, Quesenberry CP, Kovach DA: Effects of depression and selective serotonin reuptake inhibitor use on adherence to highly active antiretroviral therapy and on clinical outcomes in HIV-infected patients. J Acquir Immune Defic Syndr 2008, 47(3):384-390.

10. Asch SM, Kilbourne AM, Gifford AL, Burman A, Turner B, Shapiro MF, Bozzette SA: Underdiagnosis of depression in HIV. J Gen Intern Med 2003, 18:450-460.

11. Nogueira Campos L, De Fátima Bongolo P, Crosland Guimarães MD: Anxiety and depression assessment prior to initiating antiretroviral treatment in Brazil. AIDS Care 2006, 18(6):529-536.

12. Kaharuza FM, Bunnell R, Moss S, Purcell DW, Bikaako-Kajura W, Wamai $N$ Downing R, Solberg P, Coutinho A, Mermin J: Depression and CD4 cell count among persons with HIV infection in Uganda. AIDS Behav 2006, 10: S105-S111.

13. Olley BO, Seedat $\mathrm{S}$, Nei DG, Stein DJ: Predictors of major depression in recently diagnosed patients with HIV/AIDS in South Africa. AIDS Patient Care STDS 2004, 18(8):481-487.

14. Olley BO, Seedat S, Stein DJ: Persistence of psychiatric disorders in a cohort of HIV/AIDS patients in South Africa: A 6 month follow-up study. IJ Psychosom Res 2006, 61:479-484.

15. Rabkin JG: HIV and Depression: 2008 review and update. Current HIV/AIDS Reports 2008, 5:163-171.

16. Chandra SP, Ravi V, Desai A, Subbakrishna DK: Anxiety and depression among HIV-infected heterosexuals - A report from India. J Psychosom Res 1998, 45(5):401-409.

17. Emlet CA: Experiences of stigma in older adults living with HIV/AIDS: A mixed-methods analysis. AIDS Patient Care STDs 2007, 21(10):740-752.

18. Simbayi LC, Kalichman S, Strebel A, Cloete A, Henda N, Mqeketo A: Internalized stigma, discrimination, and depression among men and women living with HIV/AIDS in Cape Town, South Africa. SocSci Med 2007, 64:1823-1831.

19. Li L, Leea SJ, Thammawijaya P, Jiraphongsa C, Rotheram-Borus MJ: Stigma, social support, and depression among people living with HIV in Thailand. AIDS Care 2009, 21(8):1007-1013

20. Brandt R: The mental health of people living with HIV/AIDS in Africa: $A$ systematic review. Afr J AIDS Res 2009, 8(2):123-133.

21. Pearson CR, Micek MA, Pfeiffer J, Montoya P, Matediane E, Jonasse T, Cunguara A, Rao D, Gloyd SS: One year after ART initiation: Psychological factors associated with stigma among HIV-positive Mozambicans. AIDS Behav 2009, 13:1189-1196.

22. Nakasujja N, Skolasky RL, Musisi S, Allebeck P, Robertson K, Ronalds A, Katabira E, Clifford D, Sacktor N: Depression symptoms and cognitive function among individuals with advanced HIV infection initiating HAART in Uganda. BMC Psychiatry 2010, 10:44.

23. Ramrakha S, Caspi A, Dickson N, Moffitt TE, Paul C: Psychiatric disorders and risky sexual behaviour in young adulthood: Cross sectional study in birth cohort. BMJ 2000, 321:263-266.

24. Taylor SE, Peplau LA, Sears DO: Social Psychology. Eleventhth edition. New Jersey: Prentice Hall; 2003.

25. Fleishman JA, Fogel B: Coping and Depressive Symptoms among people with AIDS. Health Psychol 1994, 13(2):156-169.

26. Dew MA, Becker JT, Sanchez J, Caldararo R, Lopez OL, Wess J, Dorst SK, Banks G: Prevalence and predictors of depressive, anxiety and substance use disorders in HIV-infected men: A longitudinal evaluation. Psychol Med 1997, 27:395-409.

27. McDowell TL, Serovich JM: The effect of perceived and actual social support on the mental health of HIV-positive persons. AIDS Care 2007, 19(10):1223-1229.

28. Rotheram-Borus MJ, Stein JA, Jiraphongsa C, Khumtong S, Lee SJ, Li L: Benefits of family and social relationships for Thai parents. Prev Sci 2009, 11(3):298-307.

29. Wouters E, Van Damme W, Van Loon F, Van Rensburg D, Meulemans H: Public-sector ART in the Free State Province, South Africa: Community support as an important determinant of outcome. SocSci Med 2009, 69(8):1177-1185

30. Wouters E, Van Loon F, Van Rensburg HCJ, Meulemans H: Community support and disclosure of serostatus to family members by public-sector ART patients in the Free State Province of South Africa. AIDS Patient Care STDS 2009, 23(5):357-364.
31. Louwagie G, Bachmann M, Meyer K, Booysen FIR, Fairall L, Heunis JC: Highly active antiretroviral treatment and health related quality of life in South African adults with human immunodeficiency virus infection: a cross-sectional analytical study. BMC Publ Health 2007, 7(244):1-33.

32. Wu AW, Jacobson D, Frick KD, Clarck R, Revicki DA, Freedberg KA, ScottLennox J, Feindberg J: Validity and responsiveness of the EuroQol as a measure of health-related quality of life in people enrolled in an AIDS clinical trial. Qual Life Res 2002, 11(3):273-282.

33. Zigmond AS, Snaith RP: The hospital anxiety and depression scale. Acta Psychiatr Scand 1983, 67(6):361-370.

34. Savard J, Laberge B, Gauthier JG, Ivers H, Bergeron MG: Evaluating anxiety and depression in HIV infected patients. J Pers Assess 1998, 71(3):349-367.

35. Kavouni A, Catalan J, Brown S, Mandalia S, Barton SE: The face of HIV and AIDS: Can we erase stigma? AIDS Care 2008, 20(4):485-487.

36. Tostes MA, Chalub M, Botega NJ: The quality of life on HIV-infected women is associated with psychiatric morbidity. AIDS Care 2004, 16(2):177-186.

37. Campos LN, César CC, Guimarães MDC: Quality of life among HIV-infected patients in Brazil after initiation of treatment. Clinics 2009, 64(9):867-875.

38. Peterson RA: A meta-analysis of Cronbach's coefficient Alpha. J Consum Res 1994, 21(2):381-391.

39. Bjelland I, Dahl AA, Haug TT, Neckelmann D: The validity of the Hospital Anxiety and Depression Scale An updated literature review. J Psychosom Res 2002, 52:69-77.

40. Judd FK, Cockram AM, Komiti A, Mijch AM, Hoy J, Bell R: Depressive symptoms reduced in individuals with HIV/AIDS treated with highly active antiretroviral therapy: A longitudinal study. Aust N Z J Psychiatry 2000, 34:1015-1021.

41. Vanable PA, Carey MP, Blair DC, Littlewood RA: Impact of HIV-related stigma on health behaviours and psychological adjustment among HIVpositive men and women. AIDS Behav 2006, 10(5):473-482.

42. Wouters E, Heunis C, Van Rensburg D, Meulemans H: Physical and emotional health outcomes after 12 months of public-sector antiretroviral treatment in the Free State Province of South Africa: A longitudinal study using structural equation modelling. BMC Publ Health 2009, 9:103.

43. De Marco FJ, Ostrow DG, Di Franceisco W: General and AIDS-specific stress, coping, and psychological distress in biracial coping \& change study cohort of gay men. AIDS Behav 1999, 3(3):177-186.

44. Miller CT, Kaizer CR: A theoretical perspective of coping with stigma. $J$ Soc Issues 2001, 57(1):73-92.

45. Turner-Cobb JM, Gore-Felton C, Marouf F, Koopman C, Kim P, Isrealski D, Spiegel D: Coping, social support, and attachment style as psychosocial correlates of adjustments in men and women with HIV/AIDS. J Behav Med 2002, 25(4):337-353.

46. Kalichman SC, DiMarco M, Austin J, Luke W, Difonzo K: Stress, social support, and HIV-status and disclosure to family and friends among HIVPositive men and women. J Behav Med 2003, 26(4):315-332.

47. Onrust SA, Cuijpers P: Mood and anxiety disorders in widowhood: A systematic review. Aging Ment Health 2006, 40(4):327-344.

48. Somhlaba NZ, Wait JW: Psychological adjustment to conjugal bereavement: do social networks aid coping following spousal death? Omega 2008, 57(4):341-366.

49. Somhlaba NZ, Wait JW: Stress, coping styles, and spousal bereavement exploring patterns of grieving among black widowed spouses in rural South Africa. Journal of Loss and Trauma 2009, 14:196-210.

50. Rosenblatt PC, Nkosi BC: South African Zulu widows in a time of poverty and social change. Death Stud 2007, 31:67-85.

51. Snaith RP: The Hospital Anxiety and Depression Scale. BMC Health and Quality of Life Outcomes 2003, 1:29.

52. Wright K, Naar-King S, Lam P, Templin T, Frey M: Stigma scale revised: Reliability and validity of a brief measure of stigma for HIV + youth. $J$ Adolesc Health 2007, 40:96-98.

\section{Pre-publication history}

The pre-publication history for this paper can be accessed here: http://www.biomedcentral.com/1471-2458/12/244/prepub

doi:10.1186/1471-2458-12-244

Cite this article as: Pappin et al: Anxiety and depression amongst patients enrolled in a public sector antiretroviral treatment programme in South Africa: a cross-sectional study. BMC Public Health 2012 12:244. 